\title{
Food and Feeding Habits of the Troglobitic Carabid Beetle Rhadine subterranea
}

\author{
by ROBert W. MitChelL 1 )
}

With plates $83(1)-87$ (5)

\section{Introduction}

The purpose of this research was to determine the food source and feeding habits of the cave-dwelling beetle Rhadine subterranean (Van Dyke). Because of the scarcity of food in the cave environment, it has been generally presumed that most troglobites have generalized feeding habits. According to Vandel (1964), troglobites should be regarded as detritivores. However, scarcity of food and relative simplicity of community structure in caves do not necessarily rule out the existence of food specialists in this type ecosystem.

The genus Rhadine ranges from southern Canada to the north-central plateau of Mexico with the greatest abundance of species in the southwestern United States. The beetles are most commonly found in moist, cool habitats; under rocks and logs, in mammal burrows, and in caves. (Barr, 1960; Ball, 1960). Apparently, many species do not enter caves. Approximately 25 cavernicolous rhadinids are known including those which have been described (Barr, 1960, Bolivar y Pieltain and Hendrichs, 1964; Reddell, 1966) and those which await description (Barr, per. com.). Most of the species occur in Texas caves, especially those of the Edwards Plateau of central Texas. About two-thirds of these are microphthalmous, troglobitic species, and most appear to be restricted to caves near the Balcones Escarpment to the Edwards Plateau (Barr, 1960; Barr, Reddell, per. coms.).

Rhadine subterranea (Fig. 1) was the first of the cavernicolous rhadinids to be described, and its diagnosis is best given by Barr and Lawrence (1960). It is now known from several caves near the Balcones Escarpment in southern Williamson and northern Travis Counties, Texas. These caves are contained in the highly cavernous Edwards Limestone of the Lower Cretaceous. The

1) Department of Biology, Texas Technological College, Lubbock, Texas 79409. 
population which I studied inhabits Beck's Ranch Cave (Reddell, 1963) in Williamson County.

This cave consists of about $600 \mathrm{~m}$ of walking and crawling passage of which about one-half runs in an east-west direction and one-half in a northsouth direction. The floor lies about $11 \mathrm{~m}$ beneath the surface (at entrance level). Areas of lesser depth result primarily from large amounts of breakdown or deposits of travertine or finely powdered limestone. Temperature within the cave was approximately $20 \mathrm{C}( \pm 1)$ and was quite stable throughout the year. At no time could relative humidities of less than $100 \%$ be detected with a sling psycrometer, even during periods of extended drought. Air movement was so slight that it could not be measured, although it could sometimes be perceived at constrictions in the tunnel. All air movement probably resulted from temperature and pressure differentials between the cave and the epigeum.

A powdery calcareous deposit of varying depth and compactness covers most of the floor. For convenience I will refer to this material as "silt" although it is not an alluvium but is apparently formed in place by weathering of the limestone. The beetles were almost entirely restricted to areas of the floor where deep, uncompacted deposits of this silt were present.

Twenty-nine species of animals have been collected in Beck's Cave of which 22 are either trogloxenes, troglophiles, or troglobites. Of particular importance to the present research are the cicurinid spiders, the collembolan Pseudosinella violenta, the gryllacridids Ceuthophilus cunicularis and Ceuthophilus n. sp., the staphylinid Stilicolina n. sp., the bats Myotis velifer and Pipistrellus subflavis, and the racoon Procycon lotor.

\section{Materials and Methods}

All studies were done in the cave to insure as little alteration as possible of the natural environment of the beetles. A pit approximately $4 \mathrm{~m}$ in diameter located about $20 \mathrm{~m}$ from the cave entrance was chosen as the site for the experimental studies. The lighting required for observation and experimentation was provided by a headlamp powered by nickel-cadmium cells. Beetle activity was apparently not affected by this level of light intensity.

As will be discussed later there was much evidence pointing to cave cricket eggs as a primary food source for these beetles. This section will, therefore, be devoted to descriptions of the experiments designed to yield information on the beetles' feeding habits. Based on the experimental designs used, these experiments may be conveniently discussed under the headings Alternative Box Experiments, Oviposition Site Detection Experiments, and Foodfinding Experiments. 


\section{Alternative Box Experiments}

Several different preference experiments were carried out in boxes of the design shown in Fig. 4 . The basic experimental design was the same, and only it will be discussed here while the specific methods of individual experiments will be deferred to the Results section.

Fifty boxes were used in each experiment. Results were obtained from 48 of these while two were run as spares in the event that a beetle died during the course of an experiment, an uncommon occurrence. Silt used as the substrate in each box was sieved through hardware cloth to remove the few rocks present and then each box was filled to the top of the divider. One side of each box was then altered to provide the experimental animal a choice. That side of each box to be altered was determined randomly by the toss of a coin as was the direction faced by the altered side to eliminate any directional bias. Altered and unaltered sides were indicated by " $\mathrm{X}$ " and " $\mathrm{O}$ ", respectively, printed on the box lid.

After preparation of the boxes, a beetle was introduced into each, and at five minute intervals the side of occurrence was recorded. Beetles on the divider were recorded as occurring on that side on which its head was located. Thus, a frequency distribution of $\mathrm{X}$ and $\mathrm{O}$ occurrences was compiled.

\section{Oviposition Site Detection Experiments}

This series of experiments was designed to determine if the rhadinid beetles dig randomly in the substrate or if they show a preference for digging at potential oviposition sites, and, if digging is selective, the methods of oviposition site location.

The basic experimental design was this: Oviposition sites were simulated with a real or an artificial (Plexiglas) cave cricket ovipositor at randomly selected locations on a cricket-conditioned silt substrate. Beetles were introduced onto this substrate, and later, the locations of holes dug by the beetles were recorded.

The apparatus used in these experiments (Fig. 5) consisted of plastic boxes in which a wire grid constructed of hardware cloth (mesh size $12 \mathrm{~mm}$ ) could be suspended over the substrate. Each box was provided with a $24 \mathrm{~cm} \times$ $32 \mathrm{~cm}$ substrate of silt, the surface of which was immediately beneath, but not touching, the positioned grid. To eliminate the possibility of bias due to any edge effect, the peripheral squares were ignored in the analysis of these experiments, although the number of holes dug in peripheral squares was used in a test for edge effect. Thus the usable substrate area was $18 \times 23$ squares.

The silt surface was conditioned by female cave crickets, 20 of which were allowed to remain on the substrate for approximately one hour. 
Frequent, light tapping on the box lid induced the crickets to move about on the substrate. This general substrate conditioning was necessary to separate the effects upon beetle response of the mere presence of a cave cricket and the presence of a cricket ovipositor. After removal of the crickets, the grid was positioned and "oviposition sites" were prepared in the silt of randomly selected (by use of random numbers table) squares. These sites were prepared using either the ovipositor of a cave cricket or an artificial "ovipositor" made of Plexiglas. The use of the artificial ovipositor was designed to eliminate chemical conditioning while causing a mechanical conditioning similar to that caused by the real ovipositor. The attempt was made to approximate the action of an ovipositing cave cricket. A hole was made in the silt of a selected square and was then covered with silt dragged from the area enclosed by the square using the tip of the ovipositor. The grid was then removed and 20 beetles ( 10 males and 10 females) were introduced onto the substrate. Subsequently, at various intervals of time, the grid was positioned in each box, and the squares were recorded which contained holes dug by beetles. Data from boxes of similar treatment were pooled. The observed frequencies of holes present in untreated squares and squares of various treatment were compared statistically to expected frequencies assuming random digging. Detailed description of experiments will be deferred to the Results section.

\section{Food-finding Experiments}

Two types of experiments are included here, the finding of cave cricket eggs by rhadinid beetles and the comparative ability of rhadinids, cave crickets, and staphylinid beetles to find food.

\section{The Finding of Eggs}

The alternative boxes were used in this experiment, but for convenience rather than because of specific design. A hole was made in the silt of one side of the box with a real cricket ovipositor, and a cricket egg was pushed to the bottom of the hole with the tip of the ovipositor. The hole was then obscured by dragging silt over it with the tip of the ovipositor. Another egg was placed on the surface of the silt on the other side of the box. Four beetles were introduced simultaneously, and the egg to be located first by any beetle was entered appropriately into Cole's Closed Sequential Test Design (Cole, 1962). Individual runs were made unitl significance was indicated.

\section{Comparative Food-finding}

These experiments were run in plastic boses $12 \mathrm{~cm} \times 15 \mathrm{~cm} \times 30 \mathrm{~cm}$ containing a silt substrate. A fresh, dead cave cricket was placed in the center of the box as a food source. Two individuals, each of a different 
species, were introduced simultaneously into the box, and the first to locate the food was entered appropriately into Cole's Closed Sequential Test Design. Consecutive pairs were tested until significance was indicated. All combinations of male or female rhadinid beetle with male or female cave cricket were tested as were those of male or female rhadinid with unsexed staphylinid beetles.

\section{Results}

\section{Alternative Box Experiments}

Controls.

In the control runs the substrate of both $\mathrm{X}$ and $\mathrm{O}$ sides was of unaltered silt so that as far as could be determined the two sides differed only by designation. Observed frequency distributions of beetle occurrences on the different sides were compared with 1:1 expected distributions. Table 1 summarizes the control data. Since none of the $\mathrm{P}$ values are significant (at $\mathrm{P}=.05$ ), it is apparent that no appreciable bias was present. Comparison of experimental distributions with binomial expectation is, therefore, valid.

\section{Experiment 1.}

Treatment: Single crushed cave cricket placed in center of X side. Sex tested: Male and female. Duration: Two hours. Results: Male; first $1 / 2$ hour $-241 \mathrm{X}, 47 \mathrm{O}, \mathrm{X}^{2}=130.68, \mathrm{P}<.001, \mathrm{X}$ preferred. second $1 / 2$ hour $-125 \mathrm{X}, 163 \mathrm{O}, \mathrm{X}^{2}=5.01, \mathrm{P}<.025, \mathrm{O}$ preferred. last 1 and $1 / 2$ hours $-285 \mathrm{X}, 579 \mathrm{O}, \mathrm{X}^{2}=100.04, \mathrm{P}<.001$, O preferred. Female; first $1 / 2$ hour $-223 \mathrm{X}, 65 \mathrm{O}, \mathrm{X}^{2}=86.68, \mathrm{P}<.001, \mathrm{X}$ preferred. second $1 / 2$ hour $-177 \mathrm{X}, 111 \mathrm{O}, \mathrm{X}^{2}=15.12, \mathrm{P}<.001$, $\mathrm{X}$ preferred. last hour $266 \mathrm{X}, 310 \mathrm{O}, \mathrm{X}^{2}=3.36, \mathrm{P}>.05$, no preference (questionable $\mathrm{O}$ preference).

\section{Experiment 2.}

Treatment: Silt conditioned for 36 hours by restricting female cave cricket to X side. Sex tested: Female. Duration: Two hours. Results: 884 X, 268 O, $\mathrm{X}^{2}=329.39, \mathrm{P}<.001, \mathrm{X}$ preferred. The beetles were allowed to remain in the boxes after conclusion of the experiment, and 55 hours later the number of holes dug on $\mathrm{X}$ and $\mathrm{O}$ sides was counted. Of 578 holes, 386 were on the $\mathrm{X}$ side, giving a $\mathrm{X}^{2}=65.11, \mathrm{P}<.001$. Of 45 beetles digging more holes on one side than on the other (three dug an equal number on each side), 39 dug more holes on the $\mathrm{X}$ side, giving $\mathrm{X}^{2}=24.20, \mathrm{P}<.001$.

\section{Experiment 3.}

Treatment: Silt conditioned for $1 / 2$ hour by male cave crickets. Observations made immediately after conditioning. Sex tested: Male. Duration: One hour. Results: $410 \mathrm{X}, 166 \mathrm{O}, \mathrm{X}^{2}=103.35, \mathrm{P}<.001$, X preferred. 
Experiment 4.

Treatment: Silt conditioned for $1 / 2$ hour by female cave crickets. Observations made 18 hours later. Sex tested: Male. Duration: One hour. Results: $341 \mathrm{X}, 235 \mathrm{O}, \mathrm{X}^{2}=19.51, \mathrm{P}<.001, \mathrm{X}$ preferred.

\section{Experiment 5.}

Treatment: $\mathrm{X}$ and $\mathrm{O}$ sides conditioned for $1 / 2$ hour by female and male cave crickets, respectively. Sex tested: Male. Duration: One hour. Results: $241 \mathrm{X}, 335 \mathrm{O}, \mathrm{X}^{2}=15.34, \mathrm{P}<.001$, O preferred.

\section{Experiment 6.}

Treatment: Several female cave crickets were homogenated in a Waring blender. Silt in which this homogenate was thoroughly mixed was sprinkled over the $\mathrm{X}$ side. Untreated silt was sprinkled over the $\mathrm{O}$ side to insure comparable texture on each side. Sex tested: Female. Duration: One hour. Results: $147 \mathrm{X}, 429 \mathrm{O}, \mathrm{X}^{2}=138.03, \mathrm{P}<.001$, O preferred.

\section{Experiment 7 .}

Treatment: Female cave crickets were killed and set aside for one day. At the end of this time they had begun to decompose and produce consierable odor. One such cricket was placed in the center of each X side. Sex tested: Male and female. Duration: One hour. Results: Male; 212 X, 364 O, $\mathrm{X}^{2}=41.11, \mathrm{P}<.001$, $\mathrm{O}$ preferred. Female; $275 \mathrm{X}, 301 \mathrm{O}, \mathrm{X}^{2}=1.17$, $\mathrm{P}>.20$, no preference.

\section{Experiment 8 .}

Treatment: Artificial ovipositor holes. A device was constructed of Plexiglas and of wire the approximate diameter of a cave cricket ovipositor. Thirteen holes approximately $1 \mathrm{~cm}$ deep were simultaneously produced in the silt of the $\mathrm{X}$ side. I was unaware at the time of this experiment that an ovipositing cave cricket covers the hole with silt using the tip of the ovipositor, so the holes made with the wire were left open. Sex tested: Male and female. Duration: Two hours. Results: Male, $575 \mathrm{X}, 577 \mathrm{O}, \mathrm{X}^{2}=.0017$, $\mathrm{P}>.95$, no preference. Female; $602 \mathrm{X}, 550 \mathrm{O}, \mathrm{X}^{2}=2.34, \mathrm{P}>.10$. no preference.

\section{Experiment 9.}

Treatment: Approximately $1 / 2$ liter of silt was placed into a one liter jar along with 10 live male cave crickets. This jar was shaken continuously for 15 minutes; the crickets were removed; and the silt was sprinkled evenly 
over the X side. Untreated silt was similarly sprinkled over the O side. Sex tested: Male. Duration: One hour. Results: $318 \mathrm{X}, 258 \mathrm{O}, \mathrm{X}^{2}=6.24$, $\mathrm{P}<.02, \mathrm{X}$ preferred.

\section{Experiment 10.}

Treatment: A pattern of 13 holes similar to that in Experiment 8 was made with cave cricket ovipositors by holding an amputated abdomen with forceps. The holes were covered with silt using the tip of the ovipositor. Four boxes were prepared with each ovipositor. Sex tested: Male. Duration: Two hours. Results: $673 \mathrm{X}, 479 \mathrm{O}, \mathrm{X}^{2}=32.00, \mathrm{P}<.001$, X preferred.

\section{Oviposition Site Detection Experiments}

Two experiments, similar in basic design to that described in Methods, but differing in specific design, were run. In Experiment 1, two treatment combinations were presented simultaneously to each group of beetles while in Experiment 2, six treatment combinations were available.

In Experiment 1 the entire substrate of each box was either compacted or uncompacted and oviposition sites were simulated with either a real ovipositor or an artifical ovipositor. The ratio between the number of squares containing oviposition sites and those without them was 1:5. One control box of uncompacted silt was set up in which the "oviposition site squares" differed from the remaining squares by designation only. In Table 2 observed frequency distributions are compared to appropriate expected distributions assuming random digging, and several observed distributions are tested for homogeneity by contingency table analysis. These comparisons are based on the number of squares containing holes at the end of one day.

In Experiment 2, one-half of the substrate in each box was compacted and one-half was uncompacted. Oviposition sites simulated with real and artificial ovipositors were present in each type substrate. The ratio between squares containing the six possible treatment combinations in each box was 1 compacted silt with real site: 1 compacted silt with artificial site: 1 uncompacted silt with real site: 1 uncompacted silt with artificial site: 6 compacted silt with no site: 6 uncompacted silt with no site.

Table 3 gives comparisons of observed and expected distributions and contingency table analyses of various observed distributions from the data of Experiment 2. The first five comparisons $(\mathrm{A}-\mathrm{E})$ are based on the number of squares containing holes as revealed by counts made at the end of the first and second days. The following nine comparisons $(\mathrm{F}-\mathrm{N})$ are based on the number of squares in which beetles dug holes between the second and seventh days. Thus, squares which were dug into during the first two days were not included in the seventh day count. The expected frequency 
distributions appropriate to the seventh day data are based on the ratios of the different types which had not been dug into by the end of the second day.

The last comparison $(\mathrm{O})$ in Table 3 provides a way of testing the effect of proximity of the container wall upon hole-digging. Only squares lacking ovipositor sites were used in compiling the observed frequency distribution since the peripheral squares were intentionally excluded from treatment by ovipositors. The ratio of edge squares to central squares lacking ovipositor sites was $1: 3.44$. The observed frequency distribution is based on the number of squares containing holes at the end of seven days.

\section{Food-finding Experiments}

\section{The Finding of Eggs}

In none of the individual runs in which beetles were presented with one cave cricket egg in an oviposition site and one on the surface of the substrate was the egg on the substrate located prior to that in the ovipostor hole. Analyzed by Cole's (1962) Closed Sequential Test Design these results are significant at $\mathrm{P}=.05$. The eggs on the surface were frequently touched by antennae and maxillary palps of the beetles, but never was such an egg grasped by the mandibles of a beetle. In contrast, each egg which was located after a beetle had dug into an oviposition site was seized by the mandibles of the beetle and removed from the hole.

\section{Comparative Food-finding}

Table 4 shows the results (significant at $\mathbf{P}=.05$ ) of the series of experiments testing the comparative food-finding ability of rhadinids and cave crickets (Ceuthophilus cunicularis) and of rhadinids and staphylinid beetles (Stilicolina n. sp.). In some of these runs the rhadinid would approach within $1 \mathrm{~cm}$ of the crushed cave cricket being used as the food source and would begin to dig. In some of those few instances where the rhadinid located the food first, a cave cricket would shortly locate the food also, grasp it in its mandibles, and leap to another part of the box dislodging the rhadinid. Of the total of 99 individual comparisons, in only nine did the rhadinid locate the food first.

\section{Discussion}

It is generally recognized that in most caves populated by obligate cavernicoles food is exceedingly limited, although Vandel's (1964) views are somewhat to the contrary. His contention that other workers have over-emphasized the shortage of food is, however, based largely on an unconvincing argu- 
ment; e. g., “ . . . cavités dans lesquelles on peut récolter, par centaines, des Amphipodes, des Isopodes, des Myriapodes ou des Bathysciinés, renferment certainement des ressources alimentaires abondantes". A non-comparative consideration of the energy available in caves is of little value. Much more meaningful is the comparison of the available energy in caves relative to that in other habitats in which are found forms related to the cavernicoles. In other words, is the energy input into epigeal habitats significantly different from energy input into caves? No quantification is necessary to demonstrate that it is vastly greater in the epigeum. This limited energy source makes detailed studies of cavernicole food and feeding habits of utmost importance pursuant to many other ecological studies, especially at the population and community levels.

The food source of an animal is often not obvious. Only six times during this study did I discover a rhadinid in the process of feeding. Lacking extensive direct observations of feeding in the natural habitat, it is frequently necessary to infer the food source from clues provided by a variety of other phenomena.

No food habits are known for any of the species in the genus Rhadine, although the carabids as a group are typically predaceous. Vandel (1964) places the beetles of the carabid subfamily Trechinae at the summit of the food pyramid i. e., the carnivores) in caves. Barr (1964) reports that eggs and first instar nymphs of the cave cricket Hadenoecus subterraneus are a major food source for the eyeless trechinid Neaphaenops tellkampfi. He does not state how extensive were his observations.

Although the food which an animal will take in captivity may reveal something of the general nature of the food normally eaten, it may provide little or no information about the specific food source. The crushed cave crickets which were provided for the captive rhadinids were readily eaten, and it appeared that the beetles could have been maintained indefinitely on them. Barr (1960) has maintained $R$. caudata for two months by providing hamburger on which the beetles fed readily. The former example, therefore, is meaningful only if freshly dead cave crickets are normally available to the beetles in the cave.

A likely food source would seem to be other arthropods, especially, because of their abundance, the collembolan Pseudosinella violenta, the staphylinid Ceuthophilus cunicularis and C. n. sp. Occasionally the cave crickets used as food for captive rhadinids would not be removed promptly but would remain for several days. During this time high densities of collembolans would accumulate. I never saw a beetle seize or carry about a collembolan, and since bettle and collembolan densities were both often high, it would seem that numerous observations of feeding would have been made if the collembolans constitute a major food source for the beetles. Since my study, 
James R. Reddell (per. com.) has recorded a single observation of an individual Rhadine subterranea carrying a collembolan in its mandibles. Several times I saw encounters between very small cave cricket nymphs and rhadinid beetles, both in captivity and on the cave floor. The beetles invariably showed no response to the presence of the nymphs, even when quite close, until physical contact was made. The beetles then retreated rather than make an attempt at capture. The same observations have been made for contacts between captive rhadinids and staphylinids.

The substrate near the front of the cave had the highest concentration of particulate organic material (based on color of substrate) in the cave. Macroscopic (and presumably microscopic) fungi were accordingly the most abundant in these areas. However, distributional studies revealed a virtual absence of rhadinids from this type of substrate. The results of studies on distribution and dispersion will be reported on in detail in a subsequent paper. Suffice to say here that the cave substrate was qualitatively stratified, and within each stratum equal numbers of randomly positioned quadrats were periodically censused. Of a total of 167 bettles recorded from all strata, 108 were from one area of deep, homogeneous, uncompacted silt, 46 from another such area, while only one beetle was recorded from the stratum richest in organic debris and fungi. The paucity of sight records of rhadinids on this latter type of substrate supports the results of the distributional studies. Whether the beetles prefer some other type of substrate more, or whether they respond negatively to this type (for whatever reason), the end result is the same; they do not frequent those areas highest in particulate organic material content and fungus density. These potential food sources can apparently be disregarded.

Feces of several animals were also available. The two species of bats occurred in such low numbers (Myotis was seen only twice.) that no accumulations of guano were present. Feces of a skunk (probably Conepatus leuconotus, a common inhabitant of the area) were occasionally present near the entrance. The most abundant feces in the cave were those of the racoon. Collection in, under, and near the racoon feces was productive for several invertebrates but not for the rhadinids which were never taken near mammal feces, although beetles were locally abundant in one area where racoons frequently defecated. The only other source of an appreciable quantity of feces was the cave crickets. Cricket guano was most apparent in a limited area near the entrance, but beetles were never seen there, nor were they seen to feed on those fecal pellets present in experimental boxes the substrata of which had been conditioned by cave crickets.

The general activities of $R$. subterranea could be easily observed on those substrata of uncompacted silt where beetle density was the highest. The most frequently observed activities would seem to relate directly to the 
search for food. The beetles moved about with the antennae held forward much as in Fig. 1 with the deflexed tips continually "tapping" the substrate. The tips of the extended maxillary palps also maintained contact with the substrate. A commonly observed activity was hole-digging and it was remarkably consistent. A beetle would dig into the silt to a depth approximately equal to the length of its body by pinching loose the silt with its mandibles and removing it by pushing it posteriorly between the legs with the ventral surface of the head. The last pair of legs was used somewhat in clearing the hole but apparently not as actively as in $R$. caudata which digs (Barr, 1960) by throwing the sand out with the hind legs.

The beetles would rarely remain for an appreciable length of time in the holes but would shortly back out and continue their walking about. This digging was not an escape or hiding response caused by light or other disturbance because all undisturbed substrate of deep, uncompacted stilt in the cave was pocked with these shallow holes. Furthermore, a beetle disturbed by air movement (breath of the observer, quick movements of the hand, etc.) or by vibration (jarring of the substrate) would not then dig a hole but rather would cease its present activity and run, sometimes with surprising rapidity, from the vicinity. Perhaps coincidentally, but possibly not, the depth of the holes was within the same order of magnitude as the depth probed by the tip of the ovipositor of an egg-laying cave cricket.

Although direct observations of feeding in the natural habitat were few, they are meaningful and deserve some elaboration. The first rhadinid which I saw with an object in its mandibles proved to be carrying a cave cricket egg. A second rhadinid was later seen walking about with a cricket egg in its mandibles. After carrying the egg for about 15 minutes, it came to rest on a small chert outcrop, and during the next 30 minutes it emptied the egg of its contents. After the contents had been so depleted that the egg membrane had almost the appearance of a flat sheet, the beetle dropped the egg.

On three occasions I noticed rhadinids that were remaining in their holes for longer times than seemed usual. Each time I was able to probe into the hole alongside them without causing them to leave. I could even push the beetle away, but it would return to the same spot. In each instance I was able to locate a cave cricket egg in the silt where the beetle had been digging. At another time I discovered a rhadinid feeding on the torn end of a cave cricket femur. A cave cricket nymph appeared, seized the femur, leaped away, and began feeding on it.

Whether feeding on cave cricket eggs or on a freshly dead cave cricket, the process was similar. The mandibles and the maxillary lacinae pierced the egg and the contents were then pumped into the gut. The egg membrane was not eaten. When provided with crushed cave crickets, the rhadinids would first search about the exoskeleton until they located a break in the 
integument or a thin, membranous portion of the exoskeleton such as that of a leg joint. If at a rupture, the beetle would begin immediately to pump in tissue fluids, at times burying the head in the tissues. If at a joint the beetle would first pierce the membrane with its mandibles. A beetle locating a membranous area before locating a rupture would usually begin to feed immediately rather than search further for a point more accessible to the tissue fluids.

The experimental data gained from the alternative box experiments, the oviposition site detection experiments, and the food-finding experiments provide the most significant and detailed information on a variety of phenomena related to the feeding of $R$. subterranea. Most of the results have plausible correlations with observational data.

The initial results of Alternative Box Experiment 1 established that unengorged beetles preferred an area having food (a crushed cave cricket) over one lacking food, a hardly surprising result, and that the beetles began to feed immediately upon locating the cricket. This was apparent from observation and from the subsequent, distinct and abrupt shift in preference of the beetles as a group. It is possible that a large, immovable food source elicits immediate feeding, but when the food item can be transported (such as a cave cricket egg), the beetly may remove it to some area where the presence of another animal cannot be detected before it begins to feed. Either behavior would increase the chances for maximum food utilization.

The switch in preference after feeding to negative response to food (or the immediate vicinity of a food source) indicated by Alternative Box Experiment 1 is intriguing. The reality of the results in the last one and one-half hours of the male run cannot be questioned, and I believe that the data from the last hour of the female run probably indicate a similar result although $\mathbf{P}$ is slightly greater than .05 . One hypothesis which might be advanced to explain this is the avoidance of predators which might be attracted to the vicinity of the food source. The cicurinid spiders were frequently observed in the vicinity of racoon feces. Some constructed their webs among the fecal pellets. At least the largest cicurinid preyed on the beetles as evidenced by the presence of rhadinid exoskeletal remains beneath rocks inhabited by the spiders. A somewhat similar hypothesis consistent with observations is the avoidance of other animals attracted to the food source which might rupture the delicate dorsum of the abdomen made vulnerable by engorgement which is so extreme that the elytra failto cover a large part of the membrane (Fig 2). Puncture of this membrane might result from an attempted mating or from being kicked or stepped on by a cave cricket, both of which have been observed in encounters between rhadinids and cave crickets in captivity and in the cave. 
Alternative Box Experiments 2, 3, and 4 indicated that the rhadinids were attracted to areas where live cave crickets had once been and had in some manner "conditioned" the silt. The beetles responded positively to this conditioning whether by male or female cricket. Sufficient conditioning to elicit response occurred quite rapidly (in one-half hour in Experiments 3 and 4), and the effect persisted quite long (18 hours in Experiment 4). The distribution of holes dug in the conditioned and unconditioned silt in Experiment 2 revealed a striking preference of the rhadinids for digging into a substrate previously frequented by cave crickets.

In Experiment 5 the beetles preferred silt conditioned by male crickets over that conditioned by female crickets. I believe that this response resulted from the quantity rather than quality of conditioning. While in the boxes, the female crickets were quite placid, but the males were continually active, walking or leaping about, or scratching the substrate. This differential behavior could easily have biased the experiment.

Alternative Box Experiment 6 was designed to test for beetle response to chemical conditioning by cave crickets in the absence of mechanical conditioning, but it became instead a test for response to odor of carrion because the cricket homogenate used in the experiment had begun to decompose before the experiment was run. A strong preference for the untreated silt was shown by female rhadinids. This experiment suggested Experiment 7 in which a putrid cave cricket was placed on one side of each box. Male beetles preferred the untreated side as expected, but the females failed to exhibit a preference.

I have no explanation for the differing responses of the female beetles in Experiments 6 and 7, since it would seem that any plausible hypotheses explaining negative response to carrion should apply equally to both sexes. Negative response to carrion would remove the beetles from the presence of odors which might possibly mask those leading to a food source. This negative response might also remove the beetles from possible sources of fungal infestation. Invariably, fungi (unidentified) began to grow on dead cave crickets. When rhadinids were confined with decomposing crickets, they often became inextricably enmeshed in the fungal hyphae. At least one of these fungi was apparently a faculative parasite since some beetles became covered by a growing mycelium which eventually caused death. Death could not always be prevented by removing the carrion and its adhering fungi, although the beetles appeared to be free of hyphae.

In Alternative Box Experiment 9 chemical conditioning was adequately achieved by treating one side of each box with silt previously shaken with cave crickets, and the beetles responded positively to the treated side. Positive response to mechanical conditioning in the absence of chemical conditioning seems to be ruled out by Experiment 8 in which artificial 
ovipositor holes failed to attract the beetles. However, since these holes were left open (I did not learn until after this experiment was run that ovipositing cave crickets drag silt over the hole with the tip of the ovipositor), it is possible that this type mechanical conditioning was not of the proper quality to elicit response.

Alternative Box Experiment 10 demonstrated a preference for silt containing holes made with cave cricket ovipositors. These holes were covered by dragging silt over them with the tip of the ovipositor. Although response to the presence of these "oviposition sites" was positive, it is not possible in this experiment to separate the effects of mechanical conditioning and chemical conditioning. Furthermore, if the response was to chemical conditioning, the effects of general presence of cave crickets and specific presence of cricket ovipositors are not adequately separated.

The data from the alternative box experiments demonstrate that the beetles respond positively to the presence of cave crickets or to a substrate conditioned by cave crickets and, further, that chemoreception is important in the detection of a conditioned substrate. All the foregoing observational and experimental data indicate a definite relationship between cave crickets and the feeding of rhadinids.

The bodies of freshly dead or dying cave crickets are an obvious potential food source because of cricket abundance and because they were fed upon readily by captive rhadinids. However, the availability of this food source to the rhadinids is of critical consideration. It has already been shown that cricket bodies are not suitable food sources once odors of decomposition begin to be produced (about one day's time). The staphylinid Stilicolina sp. also feeds readily on dead crickets, and the crickets themselves are voracious feeders on their own dead.

The observation of the rhadinid's loss of the cave cricket femur to a cricket nymph suggested the comparative food-finding experiments pairing rhadinids and cave crickets, rhadinids and staphylinids. Crickets and staphylinids were the only experimental competitors used since, because of their size and abundance, they would probably be the only serious competitors for dead cave crickets in the cave. The results of these experiments (Table 4) clearly demonstrated that the rhadinids were much less efficient at locating this source of food than were either crickets or staphylinids. The hole digging of the rhadinids obviously has nothing to do with locating food on the surface of the substrate, presumably the place where dying cave crickets would fall. Since many species of staphylinid beetles bury their food, it might be suggested that the rhadinid beetles dig for crickets which have been buried by staphylinids. However, the species of staphylinid in Beck's Cave is not a burying beetle. None of the cave crickets provided as food for captive staphylinids were ever buried. Large numbers of staphylinids and cave 
crickets were taken at all seasons in pit traps (glass jars) baited with dead crickets and embedded in the substrate, but rhadinids were rarely taken.

It is probable, therefore, that while rhadinids may occasionally feed on the bodies of cave crickets, such feeding is fortuitous and is not of major importance. A primary food source of the $R$. subterranea seems apparently to be the eggs of cave crickets since this is the only inference consistent with observational and experimental data.

The oviposition site detection experiments demonstrated conclusively that when on a substrate containing oviposition sites, the rhadinids do not dig randomly but exhibit a preference for digging into these sites. Experiment 1 indicated a great proficiency for finding oviposition sites in compact silt whether these were simulated with a cricket ovipositor (a "real" site) or an artificial ovipositor (an "artificial" site) (Table 2, B and C). No differential ability in locating the two types of sites was indicated (D). In uncompacted silt the beetles showed a preference for digging into real sites (E) while they did not differentiate between squares with artificial sites and those without sites (F). However, since no significant difference was indicated in the direct comparison $(\mathrm{G})$ of the observed distributions in $\mathrm{E}$ and $\mathrm{F}$, this experiment was partially inconclusive.

In Oviposition Site Detection Experiment 2 the beetles were presented simultaneously all the combinations offered only in pairs in Experiment 1. Digging was not random but was highly selective (Table 3, A and $\mathrm{H}$ ). There was a strong preference for digging into uncompacted silt over compacted silt (B and F). The uncompacted silt in these experiments was roughly equivalent to the uncompacted silt in those areas of the cave where beetles were especially abundant, and the compacted silt was comparable to that in areas where beetles were sparse. It is suggested by these experiments and by the distributional studies which revealed a paucity of rhadinids on compacted silt strata that cave crickets oviposit primarily in areas of uncompacted silt. However, no data are available on the distribution of cave crickets' eggs in the various types of substrata in the cave.

Two days after preparation of the experiment a significantly greater number of holes had been dug into real sites than into artificial sites (D) demonstrating the importance of chemoreception. However, since the degree of silt compaction had no effect upon the proportion of holes dug into real and artificial sites ( $C$ and $\mathbf{J}$ ) but did have an effect upon the proportion of holes dug into squares with sites as opposed to squares without sites(E), it is apparent that mechanoreception is also important in oviposition site detection.

The distribution of holes dug between the 2 nd and 7 th days differed significantly from that of the first two days (Table 3, G). The proportion of total holes dug in compacted versus uncompacted silt did not change 
significantly between days two and seven (I), and neither did that of holes dug in oviposition sites in compacted versus uncompacted silt $(\mathrm{K})$ nor that of total holes dug in squares with sites versus squares without sites (L). However, there was a highly significant difference between the proportion of holes dug in real sites versus artificial sites between days two and seven (M). At day seven there was no significant difference between the numbers of holes dug into real and artificial sites (N). It is thus apparent that a decrease in actual importance of chemoreception and an increase in the relative importance of mechanoreception occurred through time. It is further possible that subsequent to day two all oviposition sites which were found were located by mechanoreception, especially since the efficiency of site location did not differ significantly from day two to day seven (There was a slight decrease in efficiency, but it was not significant.).

It must be noted that these experiments were especially biased against revealing the actual importance of chemoreception in oviposition site location. While the nature of mechanical conditioning at these simulated oviposition sites was probably not greatly different from that at an actual site in the cave, both the quality and quantity of chemical conditioning could well have been far different. The chemical attractants deposited when a cave cricket actually oviposits are possibly quite different than when an amputated ovipositor is used to simulate oviposition sites. The length of time that the ovipositor and the tip of the abdomen remains in contact with the substrate is also far greater when a cave cricket oviposits than when the real sites were simulated in these experiments. Thus, chemoreception may be more important in oviposition site detection than these experiments indicate.

The oviposition site detection experiments also demonstrated (Table 3,0) that the rhadinids show a negative edge effect in the digging of holes. It is possible that this reflects a similar response in ovipositing cave crickets, but no data are available on the latter.

It was demonstrated by Food-finding Experiment 1 in which beetles were presented with eggs on the surface of the substrate and eggs in simulated oviposition sites that the beetles do not search for the egg itself. The eggs placed on the substrate were never eaten although beetles did contact them with antennae and maxillary palps. Since only the eggs in the "oviposition sites" were eaten, it appears that the digging serves as a releaser in the recognition of the eggs as food. Recognition of the egg is probably a function of the maxillary palps since they are extended during digging (Fig. 3). Because of the abundance of tactile setae on the terminal palp segment, it is possible that mechanoreception is of greatest importance in detection of the egg. 
All the foregoing data seem to warrent the following summation of the feeding habits of this population of Rhadine subterranea.

1. Primitive plants, particulate organic material, carrion, and feces are not food sources.

2. Motile animals, regardless of size, are not an important food source.

3. Dead, but unputrified, cave crickets and possibly other invertebrates are probably a minor food source.

4. The contents of cave cricket eggs are a major food source.

5 . The beetles respond positively to a substrate frequented by cave crickets.

6. Chemoreception is important in the above response.

7. The beetles do not dig randomly but dig selectively into oviposition sites.

8. Both chemoreception and mechanoreception are important in detecting oviposition sites with mechanoreception apparently being more important in the location of older sites.

9. The beetles locate cave cricket eggs as a consequence of their search for oviposition sites.

10. Recognition of an egg as food requires a prior digging into the substrate by the beetle.

Octobre 1967 
Table 1

Alternative box control data. $\mathrm{X}^{2}$ 's and $\mathrm{P}$ 's appropriate to $\mathrm{X}$ and $\mathrm{O}$ frequencies are given for different periods of time. Succeeding periods of the stated times begin at $1 / 2$ hour intervals. Summed and heterogeneity $\mathrm{X}^{2}$ 's are based upon the $1 / 2$ hour component periods of the longer time periods.

\begin{tabular}{|c|c|c|c|c|c|c|c|c|}
\hline \multirow[b]{2}{*}{ Time period } & \multicolumn{6}{|c|}{ Male } & \multirow[b]{2}{*}{ Het $\mathrm{X}^{2}$} & \multirow[b]{2}{*}{$\mathbf{P}$} \\
\hline & X's & O's & $\mathrm{X}^{2}$ & $\mathrm{P}$ & Sum $\mathrm{X}^{2}$ & $\mathrm{P}$ & & \\
\hline 1 st $1 / 2 \mathrm{hr}$ & 141 & 147 & .125 & $>.70$ & & & & \\
\hline 2 nd $1 / 2$ hr & 147 & 141 & .125 & $>.70$ & & & & \\
\hline $3 \mathrm{rd} 1 / 2 \mathrm{hr}$ & 145 & 143 & .014 & $>.90$ & & & & \\
\hline 4 th $1 / 2 \mathrm{hr}$ & 145 & 143 & .014 & $>.90$ & & & & \\
\hline $1 \mathrm{st} \mathrm{hr}$ & 288 & 288 & .000 & 1.00 & .250 & $>.80$ & .250 & $>.50$ \\
\hline $2 \mathrm{nd} \mathrm{hr}$ & 292 & 284 & .111 & $>.70$ & .139 & $>.90$ & .029 & $>.80$ \\
\hline $3 \mathrm{rd} \mathrm{hr}$ & 290 & 286 & .028 & $>.80$ & .028 & $>.95$ & .000 & 1.00 \\
\hline $1 \mathrm{st} 11 / 2 \mathrm{hr}$ & 433 & 431 & .005 & $>.90$ & .264 & $>.95$ & .259 & $>.80$ \\
\hline 2 nd $11 / 2 \mathrm{hr}$ & 437 & 427 & .116 & $>.70$ & .153 & $>.98$ & .037 & $>.95$ \\
\hline 2 hrs & 578 & 574 & .014 & $>.90$ & .278 & $>.99$ & .264 & $>.95$ \\
\hline
\end{tabular}

Female

\begin{tabular}{|c|c|c|c|c|c|c|c|c|}
\hline Time period & X's & O's & $\mathrm{X}^{2}$ & $\mathrm{P}$ & Sum $X^{2}$ & $\mathrm{P}$ & Het $\mathrm{X}^{2}$ & $P$ \\
\hline $1 \mathrm{st} 1 / 2 \mathrm{hr}$ & 145 & 143 & .041 & $>.90$ & & & & \\
\hline 2 nd $1 / 2 \mathrm{hr}$ & 140 & 148 & .222 & $>.50$ & & & & \\
\hline $3 \mathrm{rd} 1 / 2 \mathrm{hr}$ & 140 & 148 & .222 & $>.50$ & & & & \\
\hline 4 th $1 / 2$ hr & 153 & 135 & 1.125 & $>.25$ & & & & \\
\hline $1 \mathrm{st} \mathrm{hr}$ & 285 & 291 & .062 & $>.80$ & .236 & $>.80$ & .174 & $>.50$ \\
\hline $2 \mathrm{nd} \mathrm{hr}$ & 280 & 296 & .044 & $>.80$ & .444 & $>.80$ & .400 & $>.50$ \\
\hline $3 \mathrm{rd} \mathrm{hr}$ & 293 & 283 & .017 & $>.80$ & 1.437 & $>.30$ & 1.420 & $>.20$ \\
\hline $1 \mathrm{st} 11 / 2 \mathrm{hr}$ & 425 & 439 & .227 & $>.50$ & .458 & $>.90$ & .232 & \\
\hline 2 nd $11 / 2 \mathrm{hr}$ & 433 & 431 & .005 & $>.90$ & 1.569 & $>.50$ & 1.565 & $>.30$ \\
\hline 2 hrs & 578 & 574 & .014 & $>.90$ & 1.583 & $>.80$ & 1.569 & $>.50$ \\
\hline
\end{tabular}

Table 2 .

Detection of oviposition sites, Experiment 1. The numbers are number of squares of indicated treatment containing holes dug by beetles. Counts were made at end of first day. $\mathrm{c}=$ compacted silt, $\mathrm{u}=$ uncompacted silt, $\mathrm{r}=$ oviposition site simulated with real cave cricket ovipositor, $\mathrm{a}=$ oviposition site simulated with artificial ovipositor, $\mathrm{b}=$ absence of simulated oviposition site (a "blank" square), $\mathrm{T}=$ total number of squares characterized by any following symbol or symbols. Comparison $\mathrm{A}$ is the control in which "site" differs from b by designation only.

\begin{tabular}{lrr} 
& $\mathrm{f}_{\mathrm{o}}$ & \multicolumn{1}{c}{$\mathrm{f}_{\mathrm{e}}$} \\
\hline "site" & 7 & 8.50 \\
b & 44 & 42.50
\end{tabular}

$\mathrm{X}^{2} / 1$ d. f. $=.373$

$P>.50$
B

\begin{tabular}{|c|c|c|}
\hline & $\mathrm{f}_{o}$ & $\mathrm{f}_{\mathrm{e}}$ \\
\hline $\mathrm{cb}$ & 21 & 52.50 \\
\hline cr & 42 & 10.50 \\
\hline
\end{tabular}

$\mathrm{C}$

\begin{tabular}{lrr} 
& $\mathrm{f}_{\mathrm{o}}$ & $\mathrm{f}_{\mathrm{e}}$ \\
\hline cb & 7 & 24.17 \\
ca & 22 & 4.83 \\
\hline $\mathrm{X}^{2} / 1$ & d. f. & -73.24 \\
$\mathrm{P}<.001$ &
\end{tabular}


D

\begin{tabular}{lcc} 
& $\begin{array}{c}\text { with } \\
\text { sites }\end{array}$ & $\begin{array}{c}\text { without } \\
\text { sites }\end{array}$ \\
\hline $\mathrm{f}_{\mathrm{o}}$ in A above & 42 & 21 \\
\hline $\mathrm{f}_{\mathrm{O}}$ in B above & 22 & 7
\end{tabular}

$\mathrm{X}^{2} / 1$ d. f. $=.42$ $\mathrm{P}>.50$

F

\begin{tabular}{lrc} 
& $\mathbf{f}_{\mathrm{o}}$ & $\mathbf{f}_{\mathrm{e}}$ \\
\hline ub & 54 & 57.50 \\
ua & 15 & 11.50 \\
\hline $\mathrm{X}^{2} / 1$ & d. f. $=$ & 1.28
\end{tabular}

$\mathrm{P}>.75$

G
$\mathrm{E}$

\begin{tabular}{llr} 
& f $_{\mathrm{o}}$ & \multicolumn{1}{c}{$\mathrm{f}_{\mathrm{e}}$} \\
\hline ub & 111 & 130.00 \\
ur & 45 & 26.00
\end{tabular}

$\mathrm{X}^{2} / 1$ d. f. $=16.66$

$\mathbf{P}<.001$

\begin{tabular}{llc} 
& $\begin{array}{l}\text { with } \\
\text { sites }\end{array}$ & $\begin{array}{l}\text { without } \\
\text { sites }\end{array}$ \\
\hline $\mathrm{f}_{\mathrm{o}}$ in $\mathrm{D}$ above & 45 & 111 \\
\hline $\mathrm{f}_{\mathrm{o}}$ in $\mathrm{E}$ above & 15 & 54 \\
\hline $\mathrm{X}^{2} / 1$ d. $\mathrm{f} .=.90$ & & \\
$\mathrm{P}>.75$ & &
\end{tabular}

Table 3.

Detection of oviposition sites, Experiment 2. Comparisons A-E based on data of days 1 and 2. Comparisons $\mathrm{F}-\mathrm{O}$ based on data of day 7 and of days 1 and 2 . Symbols as explained in Table 2.

A

\begin{tabular}{lrr} 
& $\mathrm{f}_{\mathrm{o}}$ & \multicolumn{1}{c}{$\mathrm{f}_{\mathrm{e}}$} \\
\hline $\mathrm{cb}$ & 4 & 43.12 \\
$\mathrm{cr}$ & 14 & 7.19 \\
$\mathrm{ca}$ & 5 & 7.19 \\
$\mathrm{ub}$ & 50 & 43.12 \\
$\mathrm{ur}$ & 29 & 7.19 \\
$\mathrm{ua}$ & 13 & 7.19
\end{tabular}

$\mathrm{X}^{2} / 5$ d. f. $=114.56$

$\mathrm{P}<.001$

E

\begin{tabular}{|c|c|c|}
\hline & $\mathrm{c}$ & $\mathrm{u}$ \\
\hline ra & 19 & 42 \\
\hline b & 4 & 50 \\
\hline
\end{tabular}

B

\begin{tabular}{lrl} 
& $\mathbf{f}_{\mathrm{o}}$ & \multicolumn{1}{c}{$\mathrm{f}_{\mathrm{e}}$} \\
\hline $\mathrm{Tc}$ & 23 & 57.50 \\
$\mathrm{Tu}$ & 92 & 57.50 \\
\hline $\mathrm{X}^{2} / 1$ & d. f. $=41.40$ \\
$\mathrm{P}<.001$
\end{tabular}

F

\begin{tabular}{lrr} 
& $\mathrm{f}_{\mathrm{o}}$ & \multicolumn{1}{c}{$\mathrm{f}_{\mathrm{e}}$} \\
\hline cb & 17 & 61.92 \\
cr & 10 & 9.32 \\
ca & 12 & 10.04 \\
ub & 68 & 58.22 \\
ur & 19 & 8.11 \\
ua & 31 & 9.40
\end{tabular}

$\mathrm{X}^{2} / 5$ d.f. $=98.91$

$\mathrm{P}<.001$
$\mathrm{C}$

\begin{tabular}{l}
$\frac{c}{c} \mathrm{u}$ \\
\hline $\mathrm{r} 14 \quad 29$ \\
\hline $\mathrm{a} \quad 5 \quad 13$ \\
\hline $\mathrm{X}^{2} / 1$ d. $\mathrm{f} .=.0042$ \\
$\mathrm{P}>.90$
\end{tabular}

D
G

\begin{tabular}{lrrrrrr} 
& cb & cr & ca & ub & ur & ua \\
\hline Day 2 & 4 & 14 & 5 & 50 & 29 & 13 \\
\hline Day 7 & 17 & 10 & 12 & 68 & 19 & 31 \\
\hline $\mathrm{X}^{2} / 5$ d.f. $=17.75$ \\
$\mathrm{P}<.005$
\end{tabular}


$\mathrm{H}$

\begin{tabular}{crc} 
& $\mathrm{f}_{\mathrm{o}}$ & $\mathrm{f}_{\mathrm{e}}$ \\
\hline $\mathrm{Tc}$ & 39 & 81.27 \\
$\mathrm{Tu}$ & 118 & 75.73
\end{tabular}

$\mathrm{X}^{2} / 1$ d. f. $=45.58$

$\mathrm{P}<.001$
I

\begin{tabular}{lrr} 
& Tc & Tu \\
\hline Day 2 & 23 & 92 \\
\hline Day 7 & 39 & 118 \\
\hline$X^{2} / 1$ d. f. & $=.63$ \\
$\mathrm{P}>.30$
\end{tabular}

$\mathrm{J}$

K

\begin{tabular}{lrr} 
& $\mathrm{c}$ & $\mathrm{u}$ \\
\hline $\mathrm{r}$ & 10 & 19 \\
\hline $\mathrm{a}$ & 12 & 31 \\
\hline
\end{tabular}

cra ura

Day $2 \quad 19 \quad 42$

Day $7 \quad 22 \quad 50$

$\mathrm{X}^{2} / 1$ d.f. $=.013$

$\mathrm{P}>.90$

L

M

$\mathrm{N}$

$\mathrm{O}$

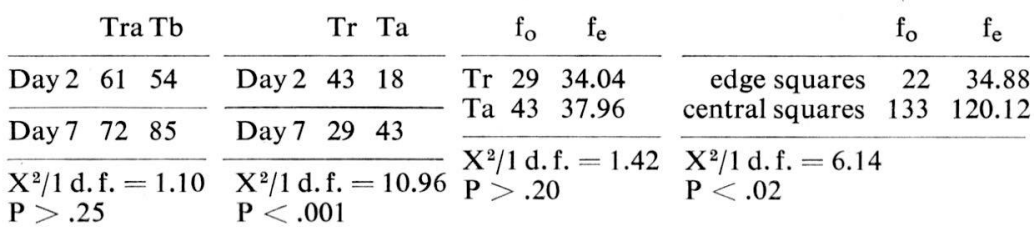

Table 4 .

Results of comparative food finding ability experiments. Cole's (1962) closed sequential test design used for analysis. Results significant at $\mathrm{P}=.05$.

Experiment series 1. All animals starv- Experiment series 2. Rhadinids starved ed for four days prior to experiments. for 14 days. Cave crickets collected from cave immediately prior to experiments.

\begin{tabular}{|c|c|c|c|}
\hline Animals Compared & "Winner" & Animals Compared & "Winner" \\
\hline $q$ rhadinid $-\delta^{\top}$ cave cricket & cricket & + rhadinid $-\widehat{\sigma}$ cave cricket & cricket \\
\hline q rhadinid $-q$ cave cricket & cricket & $q$ rhadinid $-q$ cave cricket & cricket \\
\hline$\sigma^{\top}$ rhadinid $-\sigma^{\top}$ cave cricket & cricket & $\sigma^{\top}$ rhadinid - $\sigma^{\top}$ cave cricket & cricket \\
\hline$\sigma^{\star}$ rhadinid - + cave cricket & cricket & $\sigma$ rhadinid $-q$ cave cricket & cricket \\
\hline o rhadinid - rove beetle & & & \\
\hline$\sigma^{x}$ rhadinid - rove beetle & rove & & \\
\hline
\end{tabular}




\section{SUMMARY}

Food and feeding habits of a population of the troglobitic carabid beetle Rhadine subterranea inhabiting Beck's Ranch Cave, Williamson Co., Texas, were investigated. Observational and experimental data demonstrate that a primary food source of this beetle is the eggs of cave crickets (Ceuthophilus spp.). The beetles locate eggs by selective digging into substrata where cave crickets have oviposited. Chemoreception and mechanoreception are important in the location of oviposition sites.

\section{RÉSUMÉ}

La nourriture et le mode d'alimentation d'une population du Carabique troglobie, Rhadine subterranea ont été étudiés dans la Beck's Ranch Cave, Williamson Co., Texas.

L'observation directe et l'expérimentation ont montré que les oeufs du Gryllacride cavernicole, Ceutophilus sp., constituent une principale source de nourriture.

Le Carabique les localise en creusant defaçon sélective aux endroits où l'Orthoptère a effectué sa ponte dans la grotte. La chémoréception et la mécanoréception jouent un rôle important dans la localisation exacte du lieu d'oviposition.

\section{ACKNOWLEDGEMENTS}

For their assistance and fruitful suggestions I wish to thank Mr. E. O. Beck, Dr. Bobbi Lowe, Dr. Bassett Maguire, Jr., Dr. Michael Menaker, Dr. H. Gray Merriam, Mr. James Reddell, and Dr. Bert Tribbey.

\section{REFERENCES CITED}

Ball, G. E. (1960) - Carabidae. In Arnett, R. H. (Ed.). The beetles of the United States. Washington, D. C., The Catholic Univ. of America Press.

BARR, T. C. (1959) - New cave beetles (Carabidae, Trechini) from Tennessee and Kentucky. J. Tenn. Acad. Sci., 34: 5-30.

- (1960) - The cavernicolous beetles of the subgenus Rhadine, genus Agonum (Coleoptera: Carabidae). Am. Midl. Nat. 64 (1): 45-65.

- (1964) - Cave ecology. Science, 144 (3616): $321-322$.

Barr, T. C., and J. F. Lawrence (1960) - New cavernicolous Agonum (Rhadine) from Texas (Coleoptera: Carabidae). Wasmann J. Biol., 18 (1): $137-145$.

Bolivar y Pieltain, C., and J. Hendrichs (1964) - Agoninos cavernicolas nuevos del genero Rhadine de Nuevo Leon, Coahuila y San Luis Potosi (Mexico). Cienca, 23 (1): $5-16$.

Cole, L. C. (1962) - A closed sequential test design for toleration experiments. Ecology, 43 (4) : $749-753$.

Reddell, J. R. (1963) - The caves of Williamson County. Texas Speleological Survey, 1 (2).

- (1966) - A checklist of the cave fauna of Texas. II. Insecta. Tex. J. Sci., 18 (1): $25-56$.

VANDel, A. (1964) - Biospeologie, la biologie des animaux cavernicoles. Paris, Gauthier-Villars. $1-619$.

VAN DyKe, E. C. (1918) - A new genus and species of cave-dwelling Carabidae (Coleoptera) from the United States. J. New York Entomol. Soc., 26: 179-182. 


\section{EXPLANATIONS OF PLATES 19 (1)-23 (5)}

Plate 83 (1): Rhadine subterranea. Lack of apparent eyes and the attenuation of appendages and prothorax are typical of many troglobitic carabid beetles. Notice that the tips of the maxillary palps and the deflexed tips of the antennae are in contact with the substrate.

Plate 84 (2): Engorged Rhadine subterranea. Compare with Plate 1.

Plate 85 (3): Rhadine subterranea removing cave cricket egg from silt. Notice that the terminal segments of the maxillary palps are in contact with the egg.

Plate 86 (4): Alternative box design.

Plate 87 (5): Apparatus used in the experiments on oviposition site detection. 


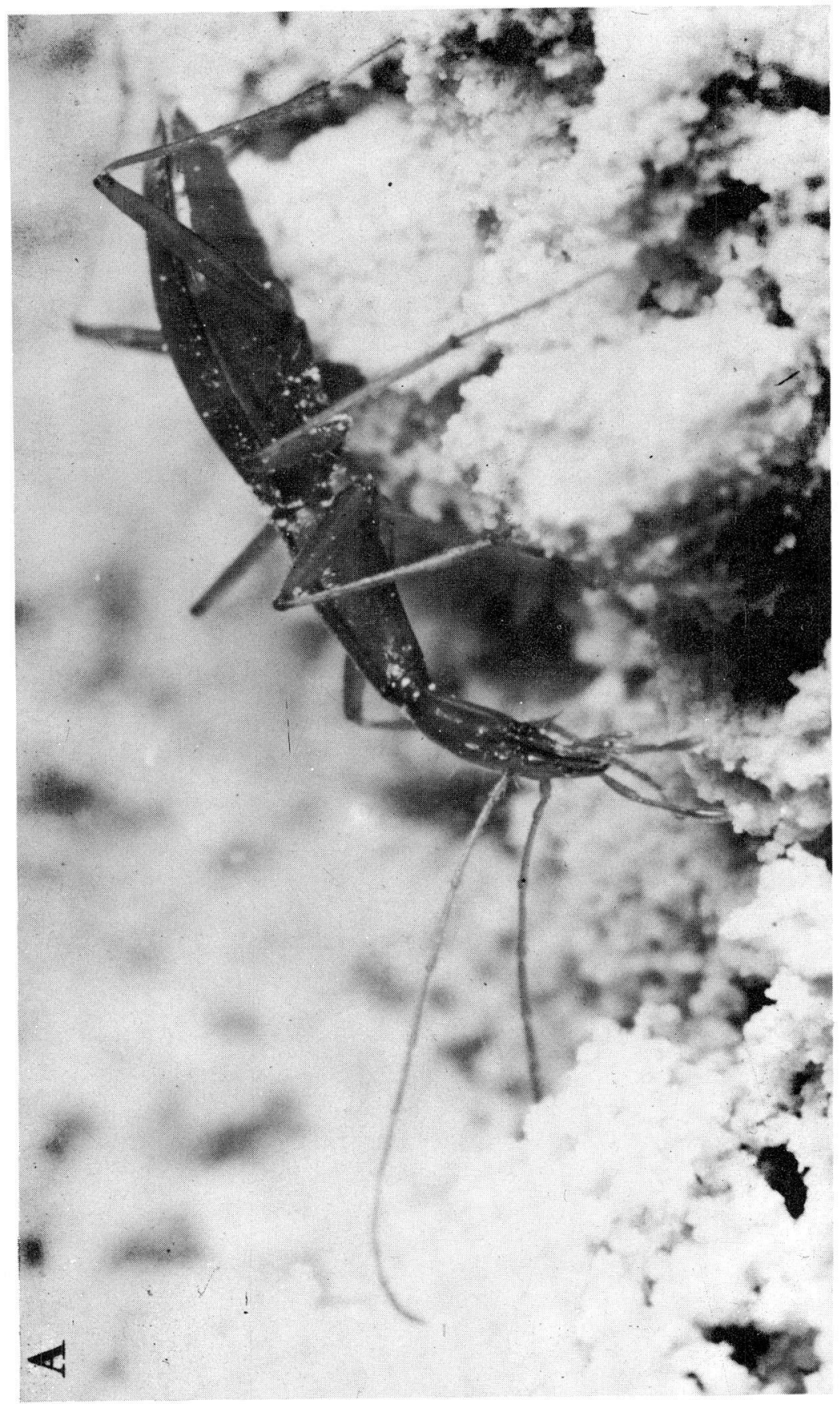




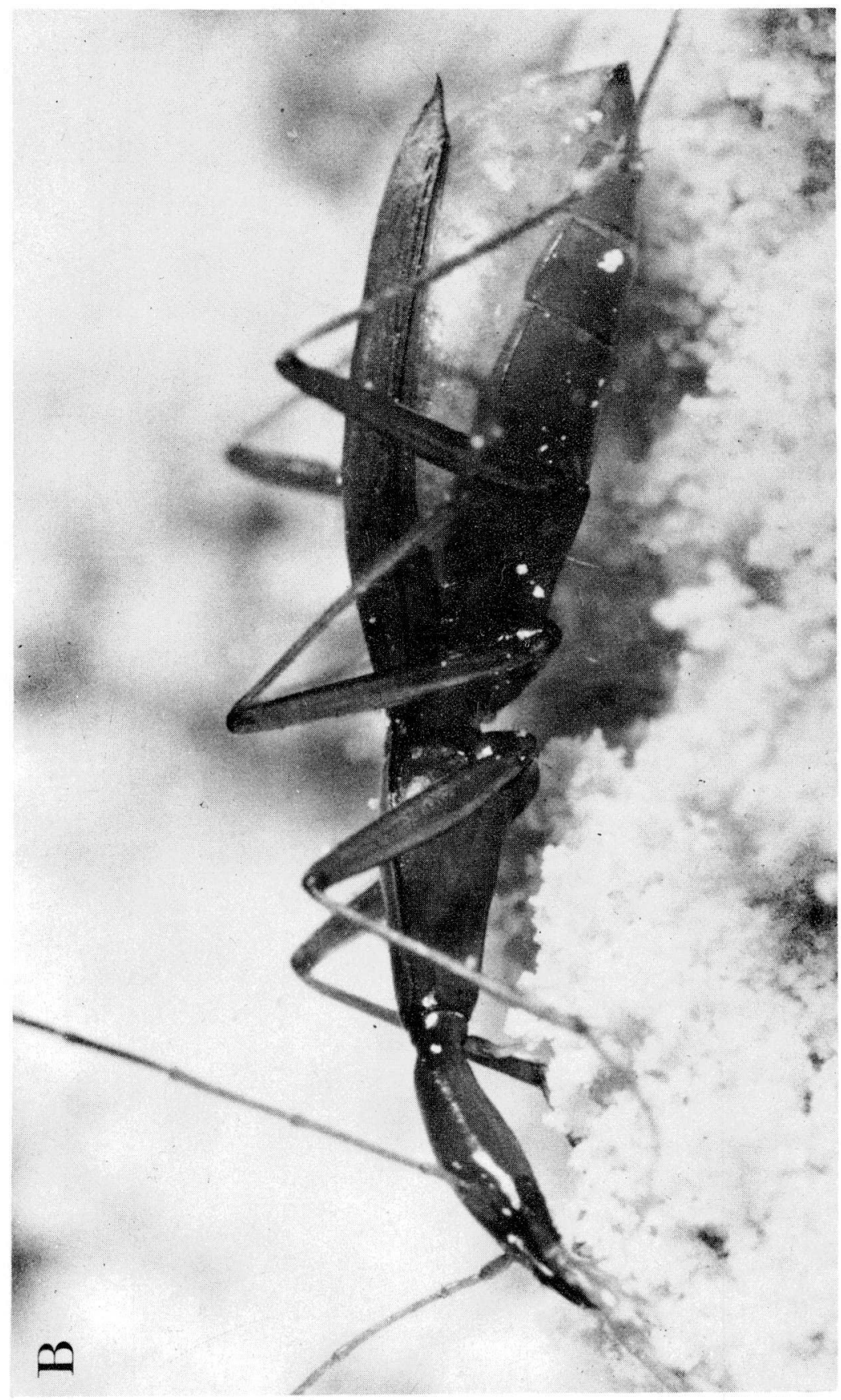




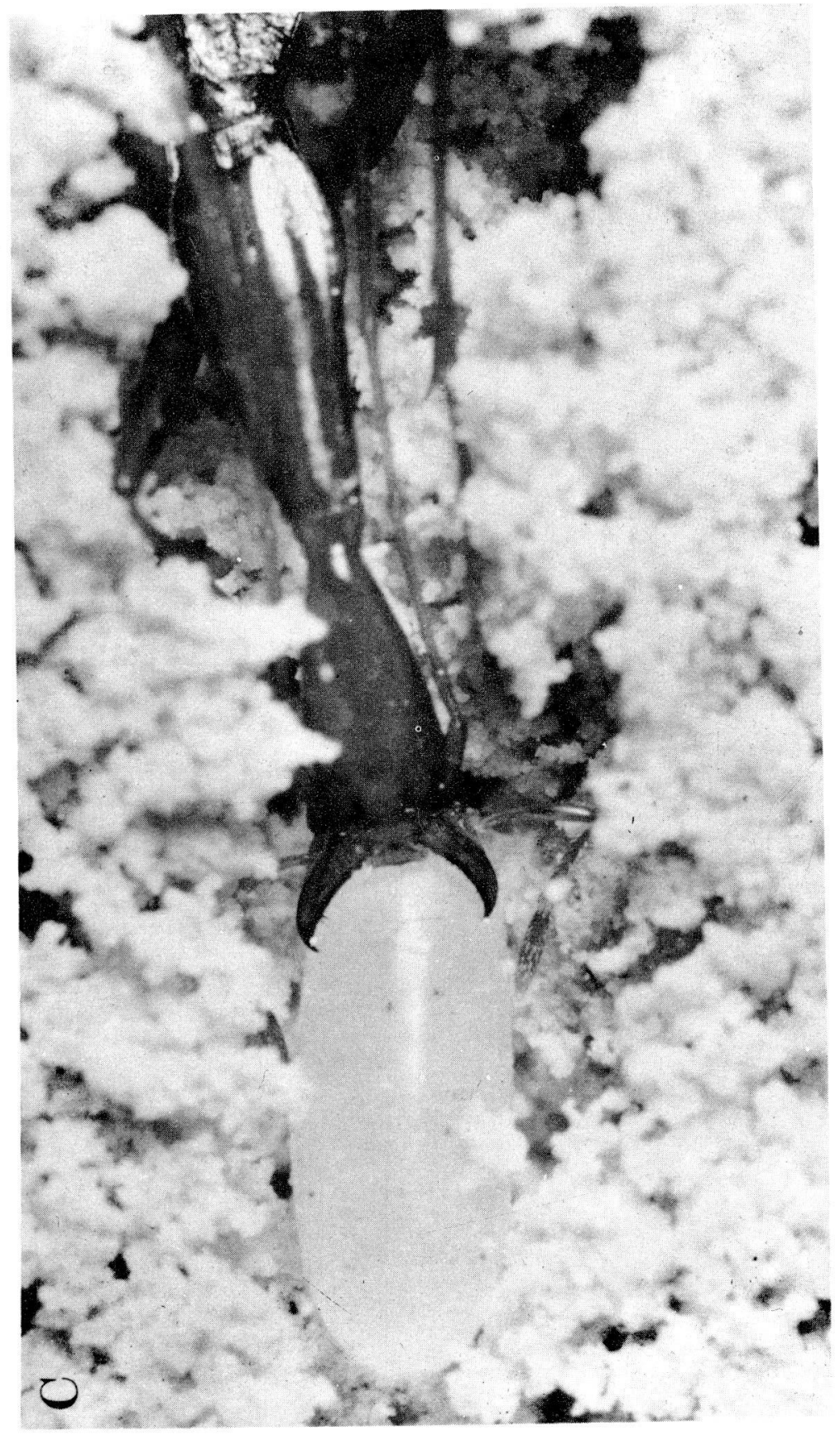




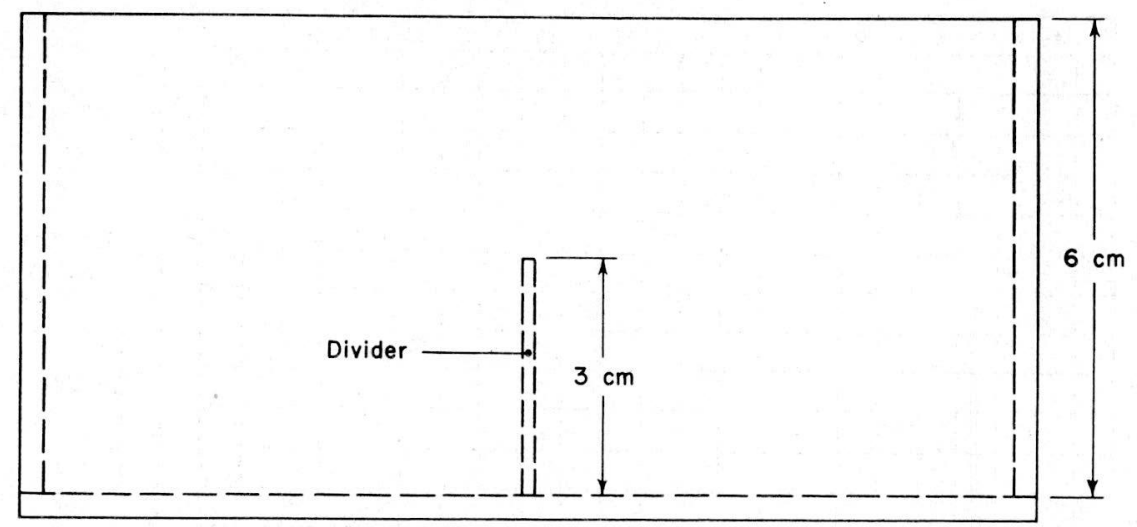

Side view
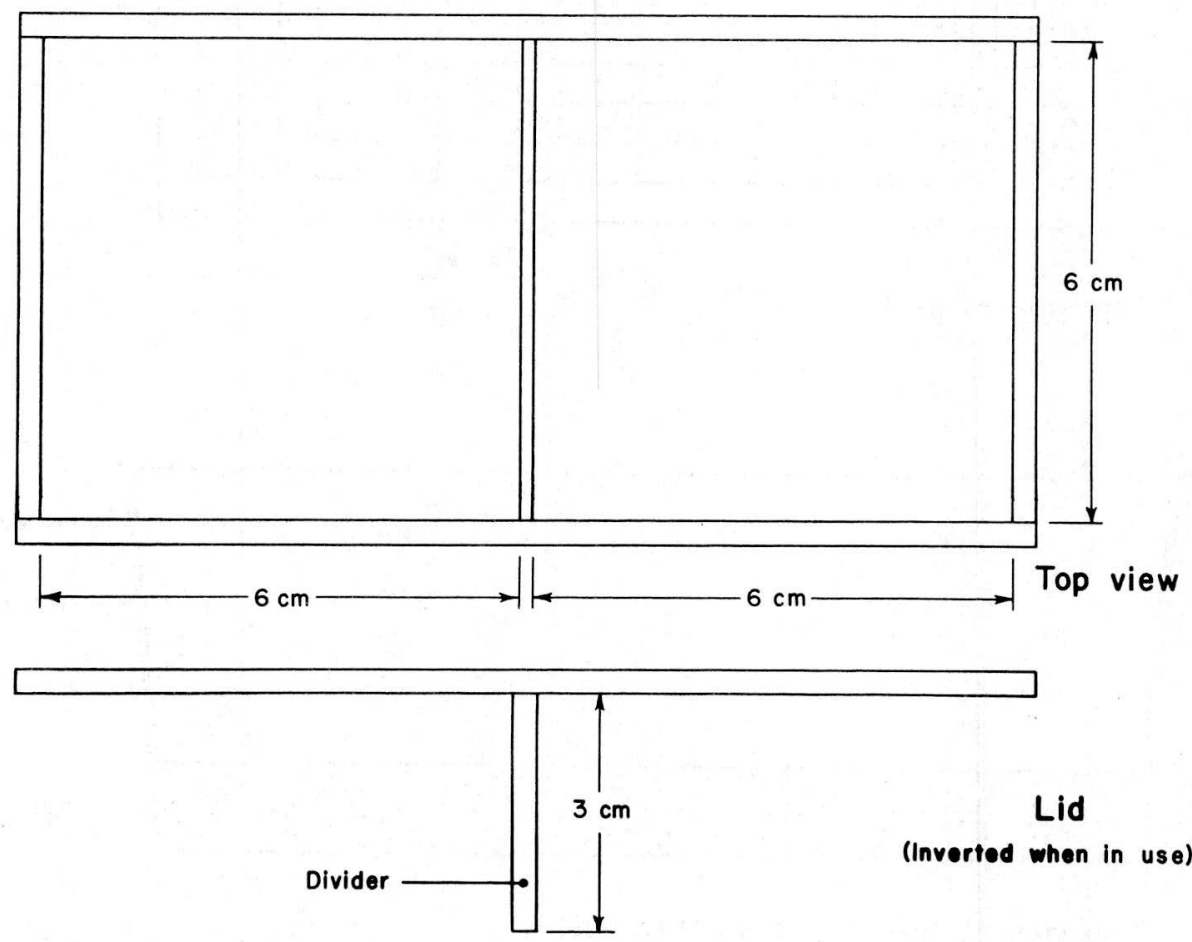


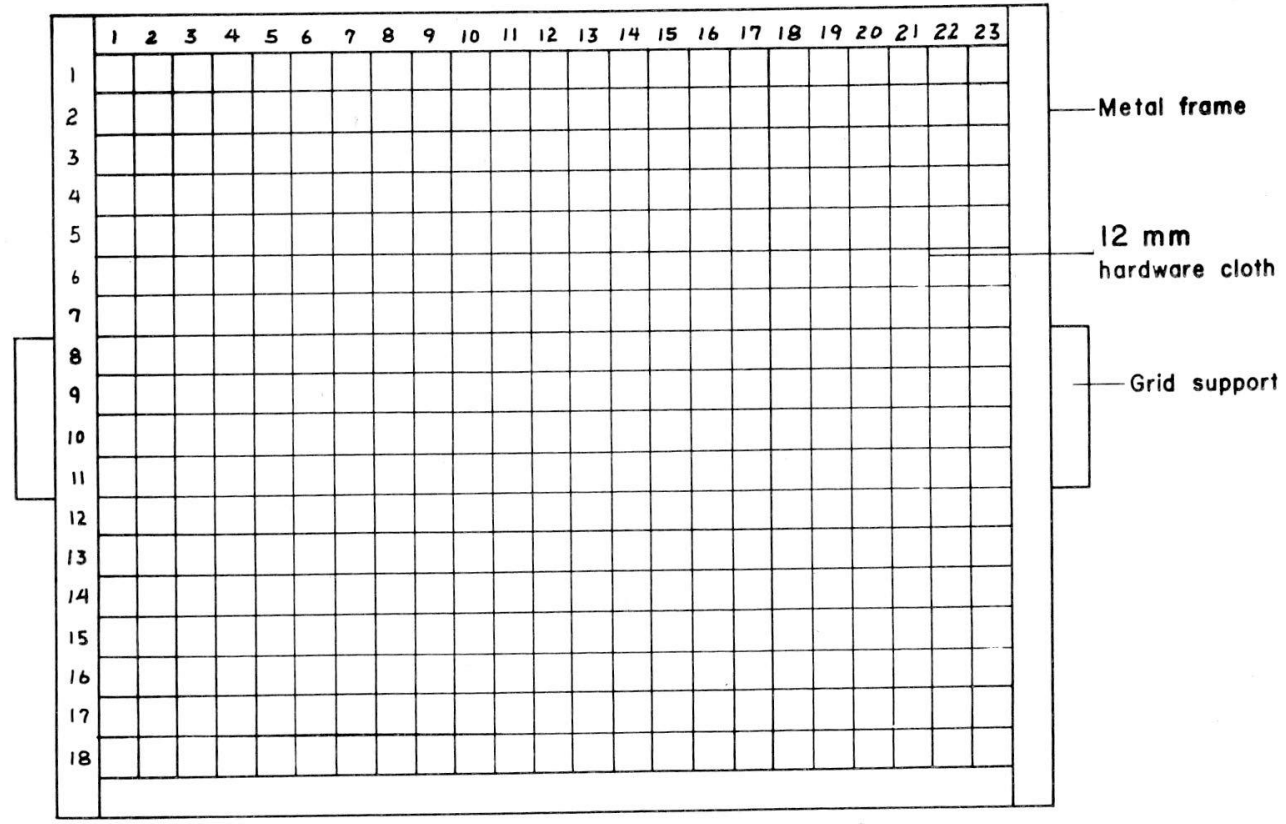

Top view of grid

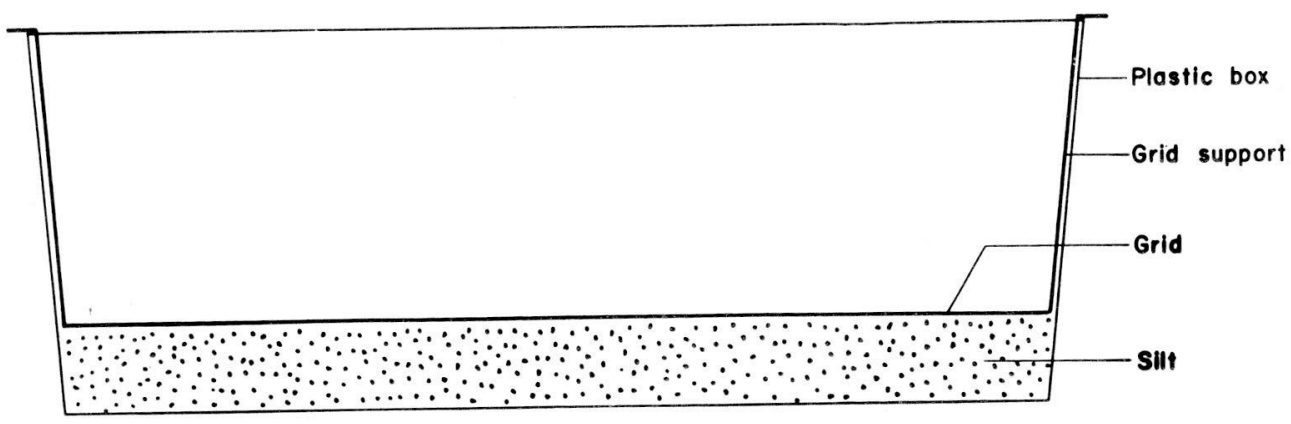

Side view of box with positioned grid 